\title{
Adequate Sleep at Night May Protect from Prostate Cancer
}

\author{
Mete Özkıdık*, Anar Ibrahimov and Tuncer Bahçeci \\ Clinic of Urology, Turkey

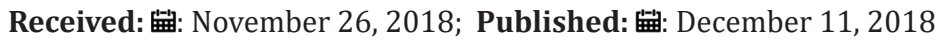 \\ *Corresponding author: Mete Özkıdık, Clinic of Urology, Turkey
}

\section{Abstract}

Introduction: Adequate sleep at night is important for immune system and its components against carcinogenesis. This study aims to discuss whether adequate night sleep may be protective from prostate cancer.

Materials and Methods: 52 males over the age of 55 without history of prostate cancer are participated. Patients are divided into two groups as having night sleep $\leq 6$ hours or $>6$ hours. Cancer rates are compared with Fisher Exact test with an accepted $p$ value of $\leq 0.05$ for significance.

Results: Due to the prostate biopsy results, patients having night sleep $\leq 6$ hours tend to have more likely prostate cancer. (p:0.041) No significant difference is detected between two groups for the mean age or other possible risk factors of prostate cancer.

Conclusion: To conclude, night sleep $>6$ hours would be a preventive measure from prostate cancer.

\section{Introduction}

Deficiency of immune system in various ways would lead to several types of cancer. Pathophysiology of carcinogenesis mainly depends on the breakaway of tumor cells from protective mechanisms of innate and adaptive immune systems [1]. These escaped cells constitute the primary site for carcinogenesis and tumoral growth [1]. Several studies highlight that adequate sleep at night is important for immune system [2]. Because it is a chance for immune system to detect tumor cells and destroy them in the appropriate time so that tumor cells would not get a chance to escape and grow. Immunotherapy is widely accepted and also performed in recent years for treatment of metastatic prostate and renal cell cancer [3]. Therefore, adequate night sleep would be a preventive measure from prostate cancer as it is a promoter of immune system.

\section{Materials and Methods}

This study is conducted with a prospective, randomized and double-blinded design in Yerköy State Hospital. 52 males over the age of 55 without any history or family history of prostate cancer and with a PSA value between 2.5 and $10 \mathrm{ng} / \mathrm{ml}$ are participated. Patients are divided into two groups as having night sleep $\leq 6$ hours (group A) and $>6$ hours (group B). Patients using dutasteride, testosterone supplement therapy or any other drug which may affect PSA value are excluded. To detect prostate cancer, ultrasound guid ed transrectal prostate biopsy is used. 12 cores are obtained from each individual regardless of their PSA value. SPSS Version 22.0 is used for all statistical analyses [4]. Fisher Exact test is used to compare the groups and $p$ value is accepted as $\leq 0.05$ for statistical significance. The study is conducted in accordance with ethical principles derived from The Declaration of Helsinki and Good Clinical Practice. An ethical approval has been obtained from the local ethical committee. In addition, all patients participated have provided their written informed consent.

\section{Results}

Mean age, PSA value, tobacco consumption are not different between group A and B. Other possible risk factors of prostate cancer such as components of metabolic syndrome are also not different between two groups. Baldness and cadmium exposure are slightly higher in group A but the difference is not statistically significant. (p:0.2). Primary end point of the study is whether cancer detection rate is different between two groups. Both prostate cancer and clinically significant cancer (Gleason Score $\geq 7$ ) rates are higher in group A. The differences are statistically significant (p:0.041 and p:0.036 respectively). Acute bacterial prostatitis presented with high fever and urinary symptoms is only seen in 1 patient. Hospitalization and conservative treatment with appropriate antibiotics administered according to the results of urine culture have provided recovery. Other adverse events such as hematospermia, hematu- 
ria or rectal bleeding are not severe and do not require medical or surgical intervention.

\section{Discussion}

Adequate sleep at night is indispensable for elder people. It is an important factor for maintaining overall health. On the other hand, more and more studies show a relation between immune deficiency and carcinogenesis recently [5]. Adequate night sleep as a well-known supporter of strong immune system would be an important preventive factor of prostate cancer. This study is important to highlight its association with prostate cancer which is an important and common public health issue. Results of the study show a significant association between night sleep and prostate cancer. The threshold value is accepted as 6 hours of sleep to discriminate less and adequate night sleep.

Participants are all over the age of 55 because of the expected age range of prostate cancer in the urologic literature. Due to the recent advances in prostate cancer treatment, we know that every patient does not require active treatment, but active surveillance is recommended for those whose biopsy results have a gleason score of $<7$. Both prostate cancer rate and significance of cancer is higher in group A. An important limitation of this study is its small sample size and short follow-up. Because of the small population of Yerköy, we were not enable to enlarge our sample size. Adequate night sleep ( $>6$ hours) would be a preventive measure from prostate cancer as it is detected less in group $B$.

\section{Conclusion}

Adequate night sleep ( $>6$ hours) would be accepted as a preventive measure from prostate cancer and recommended to patients under risk of prostate cancer. However, cohort studies with larger sample size and longer follow-up is required to determine more decisive results.

\section{References}

1. Schatten H (2018) Immunodiagnostics and immunotherapy possibilities for prostate cancer. Adv Exp Med Biol 1096: 185-194.

2. Ingram LA, Simpson RJ, Malone E, Florida-James GD (2015) Sleep disruption and its effect on lymphocyte redeployment following an acute bout of exercise. Brain Behav Immun 47: 100-108.

3. De Santis M (2018) Immunotherapy for the treatment of prostate cancer-a comeback? Urologe A 57(11): 1342-1345

4. ICR (2013) IBM SPSS Statistics for Windows, Version 22.0. Armonk, NY: IBM Corp.

5. Shapiro M, Nandi B, Gonzalez G, Prabhala RH, Mashimo H, et al. (2016) Deficiency of the immunostimulatory cytokine IL-21 promotes intestinal neoplasia via dysregulation of the Th1/Th17 axis. Oncoimmunology 6(1): e1261776.
ISSN: 2574-1241

DOI: 10.26717/BJSTR.2018.11.002173

Mete Özkıdık. Biomed J Sci \& Tech Res

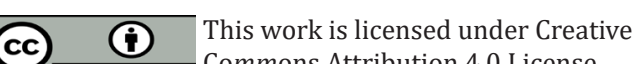

Submission Link: https://biomedres.us/submit-manuscript.php

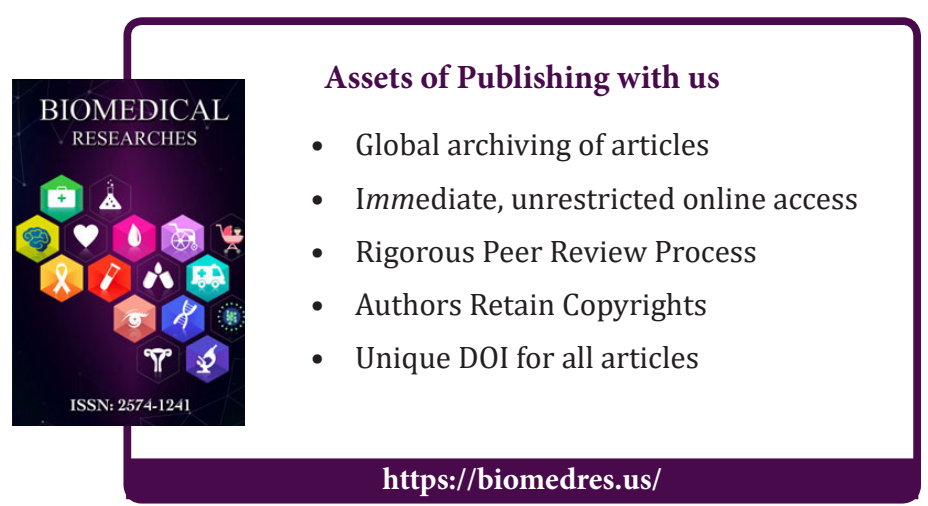

